Article to be cited as: Di Ronco, A. (2016). Media representation of regulated incivilities: Relevant actors, problems, solutions and the role played by experts in the Flemish press. Criminology \& Criminal Justice. DOI: 10.1177/1748895816646614.

\title{
Media representation of regulated incivilities: Relevant actors, problems, solutions and the role played by experts in the Flemish press
}

\author{
Anna Di Ronco ${ }^{1}$ \\ IRCP, Ghent University
}

\begin{abstract}
This article analyses the representations of regulated nuisance in a section of Flemish newspapers overtime. It identifies the groups of people who have been successful in conveying messages in and through Flemish press news, and explores the way they have represented problems of, and suggested solutions to, regulated incivilities over the years. Furthermore, against the backdrop of newsmaking criminology, it considers whether and how crime and justice experts have contributed to shaping the Flemish media discourse on regulated incivilities overtime. Overall the analysis of press news has found that the press, by giving coverage to the voices of local institutional actors, has promoted the criminalisation of nuisance and, especially, of physical incivilities. The views of criminological experts, by contrast, have remained marginal. The article concludes by suggesting how such findings present a new set of empirical and conceptual challenges for newsmaking criminology, and more generally, for public criminology.
\end{abstract}

\section{Keywords}

Regulated incivilities, media representations, media analysis, newsmaking criminology, Flemish Region (Belgium)

\footnotetext{
${ }^{1}$ Corresponding author:

Anna Di Ronco, IRCP (Institute for International Research on Criminal Policy), Department of Criminology, Criminal Law and Social Law, Ghent University, Universiteitstraat 4, 9000 Ghent (Belgium).

Email: Anna.DiRonco@UGent.be
} 


\section{Introduction}

Over the past two decades many European countries have enacted regulations aimed at sanctioning uncivil, as opposed to criminal, behaviour. This growing interest of national policymakers in regulating incivilities has been explained in the (especially UK-based) literature through reference to rising societal concerns over issues of crime and disorder (Burney, 2005; Squires, 2008). Feelings of insecurity about petty crimes and incivilities have also led the legislature of Belgium to adopt a system of 'gemeentelijke administratieve sancties' (transl.: municipal administrative sanctions) or GAS fines in 1999 (Devroe, 2012). ${ }^{2}$

Research has analysed understandings of incivilities, as well as change in dominant societal attitudes and trends about incivilities as mirrored in media outlets. A study by Peršak (2007) has, among others, shown how representations of the 'anti-social' in the British press have changed through time. Societal attitudes towards the Belgian system of local administrative sanctions as reflected in the Flemish press have also been analysed in a recent study, which found that the perceived legitimacy of sanctions also changed over time (Vander Beken and Vandeviver, 2014).

The media play a crucial role in the construction of crime, and through this suggest solutions to it (Hall, 1982). More recently, the media have facilitated the construction of anti-social behaviour as a problem. In England and Wales, for example, sensationalistic media coverage of anti-social behaviour has been a factor in labelling certain marginalised populations as deviant (Burney, 2005; Squires, 2008). As the cases of football hooliganism (Pearson, 1984) and antisocial behaviour connected to social housing (Burney, 2005; Flint and Nixon, 2006) show, societal preoccupations surrounding incivilities have been amplified by the media and have led to the adoption of punitive legislation.

Media representations of crime and crime control often rely (or rely more substantially) on the words of institutional actors, whose opinions are usually more present in the news than those of

\footnotetext{
${ }^{2}$ The GAS system (introduced by the Law of 13 May 1999) was later amended by the Laws of 7 May 2004, of 20 July 2005, and of 24 June 2013.
} 
other categories of speakers (Reiner, 2002). The media may present, however, distorted and biased versions of these views (Barak, 1988). Furthermore, Barak $(1988,1994)$ has argued that the prevalence of biased representations in the mediated discourse on crime and crime control can (at least, partly) be connected to the relative absence of the voices of criminologists and criminal justice experts, which are crucial for the critical analysis and de-construction of misinterpreted images of crime, deviance and their enforcement responses. To encourage criminologists to participate more actively and, ultimately, to correct distorted mediated images of crime and crime control, Barak (1988) introduced the 'practice' of newsmaking criminology.

Studies in newsmaking criminology have addressed criminologists' efforts to manipulate the mediated discourse on crime and crime control. However, they have done so mostly by describing criminologists' own interventions in the media (Barak, 2007b; Fox and Levin, 1993; Greek, 1994; Henry, 1994), which tend to relate to specific, time-limited crime events or issues (Barak, 1988, 1999, 2007a; Mopas and Moore, 2012). In other words, the newsmaking criminological literature seems to have under-investigated whether experts in criminology and criminal justice participate in crime-related media debates over time, in this way potentially contributing to longer term shaping of mediated discourses on crime and responses to crime.

This paper draws together interest in the regulation of incivilities, the media role in defining this as a problem and the importance of particular actors in gaining a voice and thereby influencing message shaping, and through this aims to take newsmaking criminology in a new direction. It does so, firstly, by identifying the groups of people who have been successful in conveying their message in and through Flemish press news, and explores the way they have represented problems of, and suggested solutions to, regulated incivilities overtime. Secondly, against the backdrop of newsmaking criminology (Barak, 1988), it considers whether and how crime and justice experts have contributed to shaping the Flemish media discourse on regulated incivilities over the years. Overall the analysis of press news has found that the press, by giving coverage to the voices of local institutional actors, has promoted the criminalisation of nuisance and, especially, of physical incivilities. The views of criminological experts, by contrast, have remained marginal. The article concludes by suggesting how such findings present a new set of 
empirical and conceptual challenges for newsmaking criminology, and more generally, for public criminology.

\section{Newsmaking criminology}

Recent reflections over the public role of criminologists have led to calls for, or at least growing debate about, a 'public criminology', that entails active involvement of academics in shaping public and political discourses of crime and punishment. For its focus on the public role of criminologists in the media, newsmaking criminology has also been recognised as one of the perspectives that fall within the 'idea' (Loader and Sparks, 2010: 18) of public criminology (Ruggiero, 2012; Turner, 2012).

Introduced by Barak in 1988, newsmaking criminology has been defined in Barak's later writings as the 'processes whereby criminologists use mass communication for the purposes of interpreting, informing and altering the images of crime and justice, crime and punishment, and criminals and victims' (Barak, 2001: 190). Within this criminological 'practice' (Barak, 1988), newsmaking scholars in criminology and criminal justice learn how the media operate and how to get access to them (for example, by establishing lasting relationships with journalists and media providers), as well as the communicative techniques that allow them to compete with other established actors in the process of news-making (see also Groombridge, 2007). Such techniques rely, for example, on developing journalistic and otherwise accessible skills of communication (Barak, 1988) and, in the context of television or radio news (Barak, 2007b), on understanding and advancing particular 'narrative frames'.

Newsmaking criminologists usually adopt these communicative methods to convey messages that, by providing facts or rational commentaries, radically oppose established cultural representations of crime and justice (Barak, 2007a). Edwards (2013: 212) identified four main characteristics of Barak's (2007a) newsmaking criminology: newsmaking criminological knowledge reacts to already identified newsworthy issues; de-constructs media images of crime 
and crime control by critically challenging the harmfulness of deemed serious crimes; sceptically approaches the capacity of the criminal justice system to effectively counter the crime problem; and is partisan in that it takes a side in the public debate in favour of, for example, the victims of particular types of crimes or of specific social movements. Criminological messages having these characteristics may well serve progressive ends, or the purpose of shaping public representations of, and policy approaches to, crime by empowering powerless groups (Barak, 2007a); however, they can also pursue more conservative or reactionary purposes (Edwards, 2013).

Whatever the purpose of criminologists' messages, they have not always been effective in producing alternative media discourses (see, for example, Mopas and Moore, 2012). The variable ability of those practicing newsmaking criminology to shape public discourses and policy has also been pointed out by Barak (2007a: 194), who noted that when successful, newsmaking efforts have usually involved the individual criminologist's 'appreciation for the particular format, frame and genre of specific media'. Notwithstanding its recognised limitations, this perspective seems to be based on the idea, so far relatively unchallenged in the relevant literature, that criminologists stand an actual chance of correcting distorted media images of crime and crime control, at least once they have obtained access to the media and learnt how to effectively communicate through them. Such an idea, however, underestimates the powerful role that the media have in the selection of (deemed) news-worthy stories and messages, and in their framing.

\section{Methods}

The study is divided in two parts. In the first part, the article presents a quantitative content analysis of media news published in a selection of Flemish newspapers (or newspapers that are circulated in Flanders, the northern Dutch-speaking region of Belgium, as opposed to those distributed in the southern French-speaking Region of Wallonia) between 1 January 1998 through 31 October 2014, sampling the months with the highest number of newspaper items 
published on the topics of regulated incivilities (which includes regulation, incidences, perceived causes as well as proposed solutions). This quantitative analysis leads to descriptive numerical data, which provide an indication of how many times certain actors, problems and solutions appear in the press news on regulated nuisance.

In the second part, I present a qualitative analysis of how different groups of actors have represented the problems related to the regulation of incivilities and their solutions, informed by recurrent themes extrapolated from the quantitative part of the analysis. In this second part the sample described above has been supplemented with articles that appeared outside periods of 'inflated' coverage (the months when news stories on regulated nuisance were most frequent) to include articles containing experts' opinions.

The year 1998 as the starting point of the analysis allows the study to cover the media debate preceding the adoption of the GAS legislation (enacted 13 May 1999). Newspapers were purposively selected on the basis of having the highest daily circulation and the availability of articles in the database GoPress. ${ }^{3}$ The final selection of newspapers, included quality broadsheets De Standaard (DS) and De Morgen (DM), and more popular ${ }^{4}$ titles Gazet van Antwerpen (GVA), Het Belang van Limburg (HBVL), Het Nieuwsblad (HN) and Het Laatste Nieuws (HLN). Other newspapers not included in the study may well have offered a different representation of nuisance related problems and of their solutions. This limitation has, however, been reduced by including in the selection press titles that show the higher levels of regional circulation and that are, therefore, more likely to have an influence on the audience.

\footnotetext{
${ }^{3}$ De Standaard, De Morgen, De Tijd, Gazet van Antwerpen, Het Belang van Limburg and Het Nieuwsblad have been indexed in GoPress Academic without interruption since the inception of the GAS legislation. Although Het Laatste Nieuws has been indexed starting only from 1999, it has been included in the newspapers' selection since it is the most read newspaper in Flanders since 2007. De Tijd has been omitted due to its low rate of circulation. See http://www.cim.be/.

${ }^{4}$ For a distinction between Flemish broadsheets and popular newspapers, see Raeymaeckers (2005). Velders et al. (2013: 110) emphasised that the characterisation of 'popular newspaper' (given in the study to HLN) resembles the one of the 'midmarket' dailies, rather than that of tabloids.
} 
The following keywords were used in the search: (GAS OR administrative) AND (fine OR fines OR sanction OR sanctions). ${ }^{5}$ A search strategy focused on sanctions has the advantage of allowing the research to gather all the sets of 'problems' that are associated by those who speak regarding the aforesaid regulatory measures. Newspaper articles were not included in the sample when they referred to the system of administrative fines by using keywords not utilised in this study. Through a pilot reading through newspaper articles, however, the keywords used in this research proved to be among the most widespread in articles covering problems related to regulated incivilities and their solutions.

The search resulted in 14,837 items, reduced through consecutive-unit (or day) sampling (Riffe et al., 2014) over a period of one month and deletion of identically titled articles and doubles to 1,747 items. This strategy allowed the study to capture the continuous media debate over specific 'hot topics' and incivility-related episodes, which has facilitated the identification of similarities and differences in the actors' discourses in the second qualitative part of the research. The method of sampling months with inflated amounts of relevant coverage carries, however, the risk of representing information on specific topics and events, which may be specific for that month and not be representative for the remaining years' months.

The retrieved articles were then screened for relevance and substantive data for analysis (e.g. eliminating results comprising only bullets or headlines) resulting in a final sample of 444 newspaper articles used in the quantitative content analysis.

A second keyword search was performed with the aim of identifying newspaper articles where criminologists and criminal justice experts (referred to hereafter as 'experts') were quoted, which were then added to the initial sample. 'Experts' includes researchers in the field of criminology and criminal justice working in academia, as well as those working for independent research institutions. ${ }^{6}$ Employing the other search terms as above in a string with 'AND

\footnotetext{
${ }^{5}$ It was decided not to include in the search the broad notion of 'nuisance' (overlast) added to the existing keyword search, as it would have substantially reduced the number of items retrieved (to 2,822).

${ }^{6}$ According to Barak (1988: 576), criminologists that do (or should do) newsmaking are scholars who have a 'professional knowledge' of crime and justice. Since such a professional knowledge (also) derives
} 
(criminologist OR professor OR researcher)', the same time period of sampling and screening for relevance and substantive content, produced a combined result of 479 items used in the qualitative analysis. $^{7}$

\section{What and how much of a problem: Results of the quantitative content analysis}

This section describes the results of the content analysis $(n=444)$ which establishes the basis for identifying and analysing the key issues of the qualitative analysis: What is represented as a problem? Who is at fault? What should be done? And, finally, who has a voice in answering these questions?

\section{Newspapers}

The popular titles Het Laatste Nieuws (142) and Het Nieuwsblad (119) provide the highest number of newspaper items where the topic of regulated incivilities were discussed, followed by Gazet van Antwerpen (61). An equal number of 60 items was collected in both the quality broadsheets De Morgen and De Standaard. The topic of regulated incivilities is covered only slightly by Het Belang van Limburg, which contained only 15 news items.

\section{Problem}

What. Included among the problems that are described in the items, are noise nuisance (63); illegal dumping (55) and littering (53); violent and aggressive behaviour (54); theft and

from the carrying out of independent research, in this study we considered the pursuance of research activities as the main criterion for the identification of 'experts'.

${ }^{7}$ The codes used in the computer-assisted content analysis (carried out through the software Nvivo), and illustrated in a coding frame, were 'Newspaper', 'Year', 'Who', 'Problem'(which is based on the subcodes 'What', 'Problem People', and 'Other'), and 'Solution'. 10\% of the sample (or 44 syntactical units of text) was coded by two coders with the three codes 'Who', 'Problem' and 'Solution', leading to a level of intercoder agreement, calculated through Cohen's kappa, of 65\% (64.7) (or 0.647). 
burglaries (45); parking offences (41); urinating (35); public drinking, drunkenness and abuse of drugs (25); vandalism (including graffiti and tags) (24); animal waste (23) and animal misbehaviour (11); traffic offences (20) and traffic accidents (7); posting or taping flyers and other promotional material (15); verbal disorder and abuse (8); the nuisance brought about by people procuring for and soliciting of prostitution (5); vomiting (5); feeding animals (3); fire setting (2); etc.

Problem people. Young people are referred to as a problem in 108 items, or nearly one-quarter of the news sample. Limited coverage is given to other 'problematic people' like street prostitutes (11), immigrants, asylum seekers and refugees (11), clients of prostitutes (8), activists and protesters (7), homeless (4), and football hooligans (3).

Other. Other types of problems have also been fleshed out in the news. Although the adoption and application of administrative sanctions is viewed as the preferred solution to the problem of nuisance (see below), in a number of articles they are also described as problematic. For example, the proposed or present application of administrative sanctions (including of GAS and alternative sanctions), as well as the proposed adoption or present implementation of administrative measures (which are based on the intensified controls through patrolling or CCTV cameras etc.), are seen as a problem in 163 articles. Furthermore, the adoption or expansion in the scope of local GAS regulations, and their (already approved and, for example, unclear or absurd) rules, are described as problematic in 65 items. Also the adoption of the GAS law and of its amendments are problematised (56).

Other problems highlighted in the news sample reflect the particular perspectives of local institutional actors. These speakers criticised, for example, cases dismissed by the public prosecutor and thus left to local authorities to handle through administrative sanctioning (52). Problems are also associated with the limited resources available to, and the technical or practical problems experienced by, public bodies (mostly, by municipalities and the police) in their enforcement capacities (49). 


\section{Solutions}

In the majority of the sampled items, the proposed solution coincides either with the application of administrative fines (266) to problematic individuals or behaviour, or with the adoption of other types of administrative controls against them (122). In 107 items, moreover, the offered solution consists of extending the application of GAS fines to new types of behaviours or to different categories of individuals that were previously not subject to administrative sanctioning. The adoption of regulations enforced through administrative sanctions is seen as a solution in 96 items. These quantitative data suggest that by framing the solution(s) to nuisance in terms of its regulation, overall media messages are supportive of penalising uncivil behaviour. $^{8}$

Other solutions, which are, however, lower in number, include preventive measures (94); agreement and teamwork between different public authorities (74); the adoption of local projects not envisaging a sanctioning response (32); the recruitment of extra or new personnel (22); the filing of an administrative appeal or of a judicial case (17); etc. In a number of items the adoption and implementation of the GAS law (14) and of its amendments (33) were also seen as a solution.

\section{Who is given voice}

In the sample, the voices of local institutional actors and authorities are dominant. Mayors, for example, are given a voice in 174 newspaper articles, whereas aldermen and police officials speak in 68 and 62 articles respectively. Among other local actors, there are members of the local council and of local consulting bodies (28), people in charge of running city services, departments, bodies of the municipality (26), and local public servants with (18) and without (23) sanctioning powers. Other conventional institutional actors that were given a voice included local and national politicians (49), members of the national government (45) and

\footnotetext{
${ }^{8}$ However, this finding may also be the result of the specific keyword search used in this study, which is based on sanctions.
} 
parliament (20), of the association of Flemish cities and municipalities (the VVSG) and of other public bodies (17).

Less present in the debate are the voices of private individuals, including of residents and their committees (18), those who have received a sanction (14), and laymen or people on the street who are asked to give an opinion (12). The opinions of students or young people and their committees also are relatively rarely heard, especially given the extensive framing of incivilities as linked to their own behaviour. They are directly given voice in only nine items, and their parents speak in five. Youth associations and the Children Rights Commissioner express their opinions in 14 and seven news items, respectively.

Lastly, and significantly given this article's focus, the voices of experts are almost never heard, cited in only eight items published from 2006 onwards (in the 444 sample).

\section{Who says: Results of the qualitative analysis}

Further analysis revealed two more regular and frequent narratives, namely 'getting tough on polluting behaviour' and 'setting limits to the excessive GAS system and finding alternatives', whose discourse is analysed in more depth. Focusing on these narratives allows us to check whether (and if so, how) criminologists and criminal justice experts represent problems and solutions. The two themes also allow for a sustained content analysis of the role of experts' views over time (in the 479 item sample). While the first narrative or theme is recurrent along all the considered years' inflated months, the second can be observed mostly in the inflated months of the last four selected years (i.e. from 2011 to 2014).

Getting tough on polluting behaviour

Problem: dirty cities and neighbourhoods 
Local authorities were especially successful in conveying messages about the problem of the dirtiness of cities and neighbourhoods. Such authorities include mayors, the aldermen and the members of local councils, as well as public servants working in the offices of a municipality or for one of its bodies (such as the municipal garbage collection service) in Flanders. They mostly identify the problem in the behaviour of people who throw (or leave, as in the case of animal waste) litter on the street, who dump garbage in areas where it is not allowed, who place garbage bags outside their houses irrespective of the garbage collection schedule, who fail to rightly recycle, and so forth.

Polluting behaviour is represented by them as a problem that is difficult to resolve, partly in light of the limited capacities of the municipal garbage collection services. The extent of the problem is reflected in the following representative fragment, where such difficulties are presented by a street sweeper:

'They clean all the streets inside the Singel at least once per day. And still it looks like the three hundred of street sweepers of Antwerp should start from zero every morning. Look, the first bit of the street is now done. But in an hour there will be garbage here again. You will see' (DS, 10 Oct. 2012).

The political representatives of municipalities (mayors, aldermen and councilmen), moreover, also tend to associate the problem of the dirtiness of cities and neighbourhoods with the complaints that citizens and residents raise in that respect. In their representations, the local dwellers not only complain about the presence of garbage on the streets, but also about the lenient sanctioning approach usually adopted by local authorities and other enforcement bodies in the fight against polluting behaviour. Societal expectations for the cleanliness of public places and for the punishment of minor environmental offenses mostly translate into a new set of actions or interventions taken (or proposed to be taken) by the political representatives of the municipality. One typical example is provided in the fragment below, where a councilman says:

A recent survey of the population in Tongeren shows that it [animal waste, ed.] is by far the greatest source of annoyance. 'Sixty percent of the respondents place it on top of the 
list. While just $20 \%$ gets worried about noise nuisance. The problem of animal waste is very sensitive and as a city we want to do something about it' (HBVL, 21 Apr. 2009).

As reflected in this last fragment, the negative attitudes that citizens and residents are perceived to have with respect to dirtiness in cities and neighbourhoods are also seen to be part of the problem. Such negative attitudes are also confirmed in the fragments where citizens or residents are interviewed, where they mostly provide an image of cities and neighbourhoods as dirty and made unliveable by the presence and misbehaviour of groups of young people. As exemplified in the fragment below, in doing so residents often use sensationalistic rhetoric:

'To stay in a square in the middle of a residential district until 3 in the night shouting and yelling, screaming girls, time after time leaving behind a heap of gunge and empty bottles, vomit against your front door: this is nuisance. No, "a bit" is not under discussion. Whole neighbourhoods are dominated, held awake and made filthy by careless young people' (HLN, 12 Oct. 2012).

\section{$\underline{\text { Solutions: repressive measures }}$}

Solutions to the problem of dirty cities and neighbourhoods are mostly provided by mayors, as well as by aldermen, councilmen, public servants and police officers. Although in the last fouryear period the Flemish press debate focuses on the constraints to be set to the GAS system, the imposition of such limits does not refer to the punishment of polluting behaviour, which continues to attract repressive responses. Except for mayors, the other dominant voices mainly dwell on the description of preventive and repressive actions taken by the municipality to tackle polluting behaviour. Preventive measures usually refer to the dissemination of information to residents and citizens through educational campaigns, and to the setting up of improved systems of garbage collection and sorting. Repressive interventions, by contrast, rest on the adoption of local regulations and sanctions, on an intensified police presence and surveillance in the city (or in some particular problematic urban areas), and on the establishment of new (or the reinforcement of the already existing) enforcement bodies tasked with sanctioning polluters. Although in most of the news fragments, aldermen, councilmen, public servants and police 
officers indicate preventive and repressive measures as a combined set of solutions, repressive interventions are usually given prominence in the mediatized narration. This is exemplified well in the following fragment, where one alderman speaks:

In eleven years' time the municipality of Molenbeek has become a lot cleaner. Following Christian Magerus (PS), the aldermen for the environment, sensitising and hard action are the keywords: 'In the past we couldn't sanction the people because there were no facilities [for the garbage collection], now there are 241 rubbish bins on the municipal ground. Also illegal dumpers are harshly approached. [...] 'They have paid the costs of the removal of the garbage and on top of it received a sanction. Only in this way can the problems be limited' (HN, 12 Oct. 2004).

A special focus on the need to adopt or reinforce already existing repressive measures appears commonly in the fragments where mayors are given voice. In such fragments, mayors give prominence to repressive interventions by emphasising the ineffectiveness of the preventive measures adopted in the past years, whose efforts to change the habits of the population were unsuccessful. As the following two representative fragments show, mayors mainly emphasise the uselessness of preventive measures by using sensationalistic rhetoric:

'But sensitising yields evidently too little, therefore we intervene repressively. [...] We will do anything to hunt down the offender' (HLN, 4 Mar. 2008).

'You should force behaviour to change the mentality. Waste on the streets is a good example. For too long we have tried in Antwerp in a naive way to persuade people that it is better not to throw anything on the ground, in the hope that they would also not do it anymore. [...] This proves that you should also sanction' (DS and HN, 13 Feb. 2010).

Setting limits to the excessive GAS system and finding alternatives

Problems: excessive GAS system 
From 2011, and increasingly from 2012 onwards, the GAS system has been challenged for its excessive application and for its proposed expansion.

Among the groups who are given substantial presence in the media debate over the proposed (and later approved) ${ }^{9}$ legislative changes to the GAS framework, are members of political opposition parties (and, mostly, of the Green party), youth organisations, and the Children Rights Commissioner. They problematise the GAS system by pointing at the excessive competences and powers available to local authorities, which can autonomously (and, on their account, arbitrarily) decide what is punishable as uncivil behaviour. Such discretionary powers, which are broadened by the new GAS bill, are seen to be conducive to abuses and excesses ('Often also normal forms of behaviour of young people, like hanging about with friends in a square, are bombarded as a problematic behaviour' DM, 4 Oct. 2012; 'In Hasselt and Zonhoven for example they consider already young people who sit on the edge of a bench as nuisance, elsewhere it can be that one is fined for biking without hands' HLN, 4 Oct. 2012).

The arbitrariness of the system is also emphasised by laymen and by sanctioned people whose stories are covered in the news. By mostly using sensationalistic rhetoric ('With bad will everything can be considered as disturbing behaviour' HLN, 6 Oct. 2012; 'mayors have become their own judges and find all sorts of asocial rules to facilitate discrimination' HLN, 30 May 2013), they associate the problem with the excessive exercise of powers by local authorities and their sanctioning bodies (like, for example, by police officers and other sanctioning public officials).

A different representation of the problem is offered by mayors of small towns and cities, whose voices are substantially present in the news. They identify the problem in the proposed expansion of their powers, which is put forward not only by the proponents of the new GAS legislative framework, but also by public prosecutors, who at different points in time express the intention to transfer some of their competences to the local authorities.

\footnotetext{
${ }^{9}$ The Law was passed on 23 May 2013 and entered into force on 24 June 2013.
} 
To describe the problems connected with the extension of their powers, mayors of small towns and cities use a different set of arguments. When an expansion of their competences is foreseen by a legislative act, they mostly view such changes as not necessary to enhance their daily fight against incivilities. By contrast, when the proposal to increase their competences is put forward by public prosecutors, mayors mostly make reference to the limited means and capacities at their disposal ('Such offences belong to the competence of the judicial authorities. They have the right instruments for it' DM and HLN, 3 Oct. 2014).

Especially in the last two years of the news sample (2013 and 2014), mayors increasingly tend to associate the problem with the existence of absurd rules in local regulations ('absurd restraints', HLN, 31 May 2013; 'The provisions are indeed not of this time', HLN, 31 May 2013), which have led to excessive applications of GAS fines.

Although the voices of crime and justice experts are only present in a limited number of fragments (i.e. in 15 articles, of which six are included in the years' most inflated months, whereas nine appeared in the other months) and are mostly inserted in short quotes (only two of them are commentary articles), they also participate in the media debate on the excesses of the GAS system. Experts started to generally challenge the GAS system from 2006 and, progressively in the last four considered years, when their voices have mostly appeared in the press, they have directed their critical analyses towards the legislative proposal to extend the application of GAS fines to people younger than 16 years old. By referring to research results ('Our research shows' GVA, 7 July 2006), official statistics ('the police statistics show that' DS, 31 May 2013), assessment studies ('From evaluations of the current system' DM, 4 Oct. 2012), law and juridical principles ('This conflicts with the right to assembly', 'This is contrary to article 6 of the European Convention of Human Rights' HLN, 5 Nov. 2013), experts establish a view that legislative change is not necessary or is problematic.

\section{Solution: setting limits to the system and finding alternatives}

In the last four years of the sampled period (2011-2014), mayors and other representatives of small cities and towns are especially successful in getting across messages about solutions to the 
problem of excessive applications of the GAS system. Such solutions rely on the limited application of GAS fines, which are to be imposed only in cases of (harmful, serious) nuisance such as littering and physical disorder. This message is well exemplified in the news published on the day when the changes to the GAS law were passed by the Belgian Parliament (on 31 May 2013). In the fragments below it is possible to see how local authorities try to reassure the public by making clear that cases of abuse will not happen in the future and that GAS fines are to be applied only in a reduced (and principled) fashion:

'We want to use the fines overall to penalize minor criminality', says the mayor of Waregem. 'We will not issue ridiculous fines. We set a list of what can and cannot [be fined]. In this way there will be no confusion' (HN, 31 May 2013).

'Yet we don't want excesses', clarifies Mayor Steve Vandenberghe (sp.a.). 'We intervene especially strongly against animal waste because it is a persistent problem. Strong action is especially taken against illegal dumping, but also against the illegal posting of bills and urinating in public. It seems unlikely to have any nonsensical fines whatsoever' (HLN, 31 May 2013).

A solution to the problematic introduction of new competences is also identified by mayors of small towns and cities in the non-implementation (or in the limited implementation) of the new legislative changes to the GAS framework, which are thought to be beneficial only for largesized cities. This is reflected in the representative fragment included below:

'In our police regulation we have especially provided sanctions for vandalism, noise nuisance and for the illegal occupation of the public domain', says Mayor François Saeys. 'But an increase of the sanctions will not occur. We are not a big city and the social controls in our city already work well. More severe interventions are thus not under discussion' (HLN, 5 Oct. 2012).

Although municipalities can freely decide whether or not to implement the new powers conferred by the national GAS law at local level, they do not have the same degree of discretion 
when enforcement burdens are transferred from public prosecutors to the locality. In the latter cases, mayors offer a different set of solutions to the problem: on the one hand, they mostly argue for the preservation of the status quo (where prosecutors keep and use their own competencies), on the other hand, they are not willing to allow impunity at local level. Such a discourse is exemplified in the following fragment, where a mayor (Simon Lagrange) speaks:

'We are now placed in a difficult position, because no one wants impunity in his municipality' (HLN, 7 Oct. 2014).

To resolve the perceived problem of local authorities being burdened with excessive enforcement responsibilities and powers, which had led to absurd applications of fines at local level, opposition parties, youth sections of the parties that put forward the changes to the GAS framework (sp.a. and $\mathrm{CD} \& \mathrm{~V}$ ) ${ }^{10}$, youth organisations and human rights bodies (like UNICEF, the Children Rights Commissioner and the League for Human Rights) are given voice in news mostly to support rejection of the GAS bill by members of the Parliament (e.g., 'The GAS fines already led to absurd situations, like the sanctioning of the throwing of snowballs or of ringing and running' HLN, 30 May 2013).

In the last four years of the study period, criminological experts, though much less frequently than other actors, were called upon also to provide solutions to the problem of the enlargement of the GAS framework to young(er) people. In line with the anti-GAS expansion message conveyed by other groups, experts mainly contributed to media messages that would support rejection of the new proposed amendments. The difference in the discourses of these two groups of people lies in the way they substantiate their proposed solutions: while the former group does so by mostly referring to the cases where GAS fines have been excessively applied to young people, the latter mainly draws on legal arguments and research data. This scientific knowledge is not only used by experts to support the rejection of the GAS bill. It is also utilised to suggest need for the substantial revision of the existing system, as well as to offer other types of normative solutions to the presented problem. The presence of these two sets of solutions is

\footnotetext{
${ }^{10}$ The sp.a. is a socialist party, whereas $\mathrm{CD} \& \mathrm{~V}$ is a Christian democratic party.
} 
exemplified in the two snippets included below, which show how experts (in this case, criminologist Stefaan Pleysier and criminal justice scholar Bernard Tilleman) support the revision of the GAS system by proposing normative solutions alternative to its expansion to people younger than 16 years old:

'That is why Pleysier thinks that is absurd to expand GAS fines to young people from 14 years old, without questioning the system itself. 'Especially because the nuisance fines for minors have seldom been used in practice, because [it would be] too timeconsuming. There is a whole procedure, including the mediation with the parents. Who will start that, for urinating in public? It's up to the public prosecutor to prosecute youth criminality. Wouldn't it make more sense to invest in better support for the youth prosecutor?'” (DM, 24 Jan. 2012).

'For this reason the dean considers this as also his task, and the one of the experts of his faculty, to thoroughly scrutinise the GAS legislation. 'We should see what we as Law Faculty can do against these excesses. Perhaps we could check which GAS fines are experienced as fair and introduce them in all Flanders. So that the unpredictability per municipality is halted. And obviously we should examine how we could prevent GAS fines to be incompatible with legal principles. Our professor of juvenile law and juvenile criminology Johan Put will take this on. Hopefully all this will lead to a better system', (HLN, 5 Nov. 2013).

Furthermore, experts also emphasise the role that prevention and social policy (rather than repressive sanctions) play in deterring young people from engaging in criminal and deviant behaviour. Such a role, however, is not always seen to be incompatible with the GAS system. Preventive measures can also operate in combination with, or as an alternative to, punitive sanctions at local level. An example of such a discourse is offered by the following fragment, where a criminologist (Elke Devroe) speaks:

'In this way the GAS in Antwerp is used as a lever for social policy. The young people are addressed and the fine is used as a last resort, as the young person does not live up to 
the mediation. Via mediation education is offered, leisure activities are provided, social projects are launched, partly financed by the city' (DM, 5 Oct. 2012).

\section{Conclusion}

The results of the quantitative content analysis show that representations of regulated incivilities in the Flemish press, mainly provided by more popular press outlets like Het Laatste Nieuws and Het Nieuwsblad, have been dominated by the voices of local institutional actors, with the voices of crime and justice experts remaining marginal. Press representations of the problem have mainly referred to the nuisance brought about by polluting behaviour and by noise emissions, and identified young people as the category of individuals who are responsible for posing the most of the nuisance-related problems. Furthermore, despite the adoption, application and expansion of the GAS system at local level being problematised in the news, they have mostly been presented as the main solutions to the presented problems.

The two main themes showed changing recurrence and frequency throughout the years sampled. Consistently since the inception of the GAS system, the press, by relying on the voices of local actors and authorities, has framed polluting behaviour as a problem and promoted its criminalisation. Local actors and authorities, in particular, have described physical incivilities as a growing source of concern, and offered solutions that are based on prevention and, mostly, on repression. Political representatives of the municipality (like mayors, aldermen and councilmen) have also added some elements to the described problem by associating it with the perceived negative attitudes of the public. In order to answer the perceived pressures exercised on them by citizens and residents, mayors have especially emphasised the importance of adopting repressive interventions targeting polluting behaviour.

In the last four years, however, press news has increasingly focused on the excesses of the GAS system, producing messages about the limits that ought to be posed to such a system. Such sanctioning limits, however, are only directed at uncivil conduct other than polluting behaviour. 
In contrast, and also during the last four years of the study period, polluting behaviour has hardened as the exemplary case of nuisance behaviour that ought to be subject to administrative sanctioning.

This study also has shown how different groups of actors have participated in the debate. Mayors of small towns and cities have problematised the proposed expansion of their competences on the basis of a lack of a practical need or of their limited local capacities. They mainly identified their intention not to exercise their new powers, or to do so only when strictly needed (for example, to avoid impunity).

Other groups have appeared in media coverage to convey and consolidate opposition to extending and expanding local sanctioning powers to young people. These groups included opposition parties, human rights bodies and youth associations.

The role of crime and justice experts was much more limited, at least in regard to the number of articles where they have appeared. In some ways, expert media messages in the last four years of the study period (when they have mostly been given coverage in the press) largely supported the perspectives of other groups in problematizing the expansion of the GAS system to younger people. In this, they fulfilled Edwards (2013) criteria of reacting critically and sceptically, as well as taking a partisan stance. Furthermore, experts in the last four considered years also seemed to use the opportunity of commenting on proposals of expanding GAS to raise more fundamental questions about regulation of incivilities and of justice in general. Alongside rejection of the GAS bill, they proposed (and ultimately hoped for) grounded, thorough, analyses of the existing system that might lead to its substantial revision. They connected the GAS framework to fundamental legal principles and to individuals' exercise of rights, and identified other strategies aimed at effectively addressing uncivil behaviour of young people.

In conclusion, the results of this study have shown that the press has tended to select the messages of local institutional actors, and to frame stories of nuisance behaviour according to points of view mainly been centred on the criminalisation of uncivil (and, especially, of polluting) behaviour. By contrast, the research has found only minimal coverage of experts' 
critical opinions, which have relatively been absent in the press until 2006 and have been very limited even in the last four years of the study period, when the press began to problematize the system of administrative fines. In essence, what these findings suggest is that experts' newsmaking messages, which tend to challenge the system of administrative sanctions, may be incompatible with the press's way of news-making on this topic, which has been mainly based on the promotion of mechanisms of nuisance criminalisation. As a consequence, the results seem to challenge the idea, on which newsmaking criminology is premised, that experts can have a public role in the media and manipulate their representations of crime and punishment by learning specific communicative methods and techniques: regardless of how they do that, it is perhaps what they say that may, at times, be irreconcilable with the media framing on certain crime-related topics. However, this research also shows that when experts are given a voice in news coverage (as in the last four considered years) they have tended to develop frames that connect issues like anti-social behaviour to wider and deeper questions of justice and social control. It may be useful for newsmaking criminological research to begin exploring expert media engagement over time and across issues to consider whether this offers a route of impact.

\section{Acknowledgments}

I would like to thank Prof. Dr. Nina Peršak and Prof. Dr. Gert Vermeulen (IRCP, Ghent University) for their insightful guidance on the earlier drafts of this article. I am also sincerely grateful to the three anonymous reviewers for their constructive comments, and to the editor Dr. Sarah Armstrong for her precious feedback and many suggestions on the article during its final revision stage. 


\section{References}

Barak G (1988) Newsmaking criminology: Reflections of the media, intellectuals, and crime. Justice Quarterly 5(4):565-587.

Barak G (1994) Media, Process, and the Social Construction of Crime: Studies in Newsmaking Criminology. New York: Garland.

Barak G (1999) Constituting OJ: Mass mediated trials and newsmaking criminology. In: Henry S and Milovanovic D (eds) Constitutive Criminology at Work: Applications to Crime and Justice. Albany: State University of New York Press, pp. 87-110.

Barak G (2001) Newsmaking criminology. In: McLaughlin E and Muncie J (eds), The Sage Dictionary of Criminology. London: Sage, pp. 190-191.

Barak G (2007a) Doing newsmaking criminology from within the academy. Theoretical Criminology 11(2): 191-207.

Barak G (2007b) Mediatizing law and order: Applying Cottle's architecture of communicative frames to the social construction of crime and justice. Crime, Media, Culture 3(1): 101109.

Burney E (2005) Making People Behave: Anti-Social Behaviour, Politics and Policy. London: Routledge.

Devroe E (2012) A swelling culture of control? The genesis and the application of the law on incivilities in Belgium. In: Ponsaers P (ed) Social Analysis of Security. Financial, Economic and Ecological Crime - Crime (In)security and Distrust - Public and Private Policing. The Hague: Eleven International Publishing, pp. 355-367. 
Edwards P (2013) How the news was made: The Anti-social Behaviour Day Count, newsmaking criminology and the construction of anti-social behaviour. Critical Criminology 21(2): 211-225.

Flint J and Nixon J (2006) Governing neighbours: Anti-social behaviour orders and new forms of regulating conduct in the UK. Urban Studies 43(5-6): 939-955.

Fox JA and Levin J (1993) How To Work With the Media. Thousand Oaks: Sage Publications.

Greek C (1994) Becoming a media criminologist: Is "newsmaking criminology" possible? In: Barak G (ed) Media, Process, and the Social Construction of Crime: Studies in Newsmaking Criminology. New York: Garland, pp. 265-286.

Groombridge N (2007) Criminologists say...: An analysis of UK national press coverage of criminology and criminologists and a contribution to the debate on 'Public Criminology'. The Howard Journal of Criminal Justice 46(5): 459-475.

Hall S (1982). The rediscovery of ideology: Return of the repressed in media studies. In: Bennett T, Curran J and Woollacott J (eds), Culture, Society and the Media. London: Methuen, pp. 56-90.

Henry S (1994) Newsmaking criminology as replacement discourse. In: Barak G (ed) Media, Process, and the Social Construction of Crime: Studies in Newsmaking Criminology. New York: Garland, pp. 287-315.

Loader I and Sparks R (2010) Public Criminology? London: Routledge.

Mopas M and Moore D (2012) Talking heads and bleeding hearts: Newsmaking, emotion and public criminology in the wake of a sexual assault. Critical Criminology 20(2): 183196.

Pearson G (1984) Hooligan: a History of Respectable Fears. New York: Schocken Books. 
Peršak N (2007) Representations of the Anti-Social. M.Phil. thesis, University of Cambridge, UK.

Raeymaeckers K (2005) Letters to the Editor: A Feedback Opportunity Turned into a Marketing Tool An Account of Selection and Editing Practices in the Flemish Daily Press. European Journal of Communication 20(2): 199-221.

Reiner R (2002) Media made criminality: The representation of crime in the mass media. In: Maguire M, Morgan R and Reiner R (eds) The Oxford Handbook of Criminology. Oxford: Oxford University Press, pp. 302-340.

Riffe D, Lacy S and Fico F (2014) Analyzing Media Messages: Using Quantitative Content Analysis in Research. London: Routledge.

Ruggiero V (2012) How public is public criminology? Crime, Media, Culture 8(2): 151-160.

Squires P (2008) ASBO Nation: The Criminalisation of Nuisance. Bristol: The Policy Press.

Turner E (2012) Beyond 'facts' and 'values': Rethinking some recent debates about the public role of criminology. British Journal of Criminology 53(1): 149-166.

Vander Beken T and Vandeviver C (2014) When things get serious. Reflection on the legitimacy of local administrative sanctions in Belgium. In: Peršak N (ed) Legitimacy and Trust in Criminal Law, Policy and Justice: Norms, Procedures, Outcomes. Farnham: Ashgate, pp. 35-49.

Velders K, Joye S, Biltereyst D, Bonte T and Delcart E (2013) (Un) covering Poland between PR and presidency: A quantitative content analysis of print news coverage of the Polish EU presidency in Flanders. Central European Political Studies 3: 109-120. 